\title{
STUDY ON THE APPLICABILITY OF THE MODIFIED TOKUHASHI SCORE IN PATIENTS WITH SURGICALLY TREATED VERTEBRAL METASTASIS
}

Jeferson Luis Mattana', Rosyane Rena de Freitas', Glauco José Pauka Mello², Mário Armani Neto², Geraldo de Freitas Filho², Carolina Bega Ferreira ${ }^{3}$, Carolina Novaes ${ }^{3}$

\begin{abstract}
Objective: To present the results obtained from surgical treatment of patients with vertebral metastases, comparing them with the modified Tokuhashi score in order to validate the applicability of this score for prognostic predictions and for choosing surgical treatments. Methods: This was a retrospective study on 157 patients treated surgically for spinal metastasis in Erastus Gaertner Hospital in Curitiba. The Tokuhashi score was applied retrospectively to all the patients. The patients' actual survival time was compared with the expected survival time using the Tokuhashi score. Results: There were 82 females and 75 males. The most frequent location of the primary tumor was the breast. The thoracic region was involved in $66.2 \%$, lumbar region in $65.6 \%$, cervical region in $15.9 \%$ and sacral region in $12.7 \%$. All the patients underwent surgical treatment. The most frequent indication for treatment was intractable pain
\end{abstract}

(89.2\%). There was partial or complete improvement in a majority of the cases $(52.2 \%)$. Out of 157 cases studied, $86.6 \%$ died. The maximum survival time was 13.6 years, the minimum was 3 days and the mean was 13.2 months. The following frequencies of Tokuhashi scores were found among the operated cases: up to 8 points, 111 cases; 9-11 points, 43 cases; and $12-15$ points, three cases. The mean survival time in months for all 157 patients according to the Tokuhashi score was: 0-8 points, 15.4 months; 9-11 points, 11.4 months; and $12-15$ points, 12 months. Conclusion: Unlike the nonsurgical approach recommended by Tokuhashi for patients with lower scores, this group in our study was sent for surgery, with better results than those of non-operated patients reported by Tokuhashi.

Keywords - Neoplasm Metastasis; Spine; Survivorship (Public Health)

\section{INTRODUCTION}

With the progressive increase in overall survival among patients with bone metastasis, oncologists are increasingly faced with cases of secondary bone lesions. Knowledge of the principles for treating such lesions therefore becomes necessary, so that patients can be provided with improved quality of life ${ }^{(1)}$.

The aim in treating metastatic bone lesions is to provide patients with improved quality of life through controlling pain and achieving partial or full functional recovery ${ }^{(2,3)}$.
Vertebral metastatic disease is difficult to treat, and the prognosis for the patient's life is the main factor in making therapeutic decisions ${ }^{(3)}$. The treatment options include conservative measures without surgery, such as hormone therapy, chemotherapy/radiotherapy and palliative treatment for pain; and surgical measures, which include complete excision of the lesion, replacement of the vertebra with an endoprosthesis and decompression and stabilization by means of posterior and/or anterior routes.

There is a consensus that surgical intervention is

1 - General Surgeon. Oncological Surgery Residents at Hospital Erasto Gaertner, Curitiba, PR, Brazil.

2 - Orthopedist in the Oncological Orthopedics Service, Hospital Erasto Gaertner, Curitiba, PR, Brazil.

3 - Medical Students at PUC, Curitiba, PR, Brazil.

Work performed at Hospital Erasto Gaertner, Curitiba, PR.

Correspondence: Rosyane Rena de Freitas - Travessa Frei Caneca, 105, apto. 44, Centro - 80010-090 - Curitiba, PR. E-mail: rosyanerf@yahoo.com.br

Work received for publication: June 09, 2010; accepted for publication: October 18, 2010.

The authors declare that there was no conflict of interest in conducting this work 
indicated in the following cases of vertebral metastatic lesion: spinal cord compression with myelopathy; vertebral instability with intractable mechanical pain; dislocated fractures of the spine; radiculopathy with progressive or uncontrollable symptoms; tumor growth even after radiotherapy; and direct extension of the primary tumor in the spine, for example in cases of Pancoast tumor ${ }^{(4,5)}$.

Strategies for surgical treatment of vertebral metastases have been determined according to the prognosis for each patient's life. One way to determine these patients' prognosis is to use the Tokuhashi score, which has recently been revised. This takes into account six parameters that measure the severity of the clinical picture: 1) general condition; 2) number of bone metastases outside of the spine; 3 ) number of metastases in vertebral bodies; 4) metastases to important internal organs; 5) primary site of the cancer; and 6) paralysis according to the Frankel scale (Box 1). Each parameter is graded with score of between 0 and 2 points. Zero signifies a poor prognosis ${ }^{(6,7)}$. From the scores obtained, the patients are allocated to different survival prognosis groups: from 0 to 8 points, six months of survival; from 9 to 11 points, six to twelve months of survival; and from 12 to 15 points, more than twelve months of survival.

Box 1 - Classification of the patients based on the initial neurological condition, according to Frankel.

\begin{tabular}{|l|}
\hline \multicolumn{1}{|c|}{ FRANKEL CLASSIFICATION } \\
\hline $\begin{array}{l}\text { A - Absence of motor or sensory function below the level of the } \\
\text { lesion }\end{array}$ \\
\hline $\begin{array}{l}\text { B - Absence of motor function, but with some degree of sensitivity } \\
\text { preserved below the level of the lesion }\end{array}$ \\
\hline C - Come degree of motor function but without practical usefulness \\
\hline D - Useful motor function below the level of the lesion \\
\hline $\begin{array}{l}\text { E - Normal sensory and motor function, although there may be } \\
\text { some abnormality of reflexes }\end{array}$ \\
\hline
\end{tabular}

With regard to treatment, choosing the ideal therapy continues to be a challenge, but this can be facilitated through standardizing the approach based on scales like the Tokuhashi score ${ }^{(8,9)}$.

Keeping patients in bed for several days when they are affected by metastatic lesions in the spine cannot be accepted. In such situations, there would be a high likelihood of evolution involving deep vein thrombosis, pulmonary thromboembolism, pneumonia, atelectasis and other clinical complications that put the patient's life into immediate risk. Physicians have the duty to intervene at the right moment and with the necessary degree of aggressiveness, because the evolution of the condition often will not allow future interventions and such patients end up progressing to death under very poor conditions in terms of quality of life.

The aim of this study was to present the results obtained from treating patients with vertebral metastases surgically, comparing their real length of survival with the length of survival expected according to the modified Tokuhashi scale, for each score group, in order to validate the applicability of this scale for prognostic predictions and for choosing the surgical therapy.

\section{MATERIAL AND METHODS}

Between the years 1993 and 2008, 157 patients with metastatic disease in the spine were assessed and treated surgically at our service. In conformity with the routine protocol, they underwent computed tomography scans on the cervical, thoracic and lumbar-sacral spine, in order to analyze all segments of the spine, as well as examinations to investigate other metastatic sites and to investigate primary sites if the primary site was unknown. The following data were tabulated: age, primary tumor, sex, location of the metastasis, preoperative neurological state according to the Frankel scale (Box 1), improvement in pain after the operation using a visual analogue pain scale (Figure 1) and the final evolution of the case (survival or death).

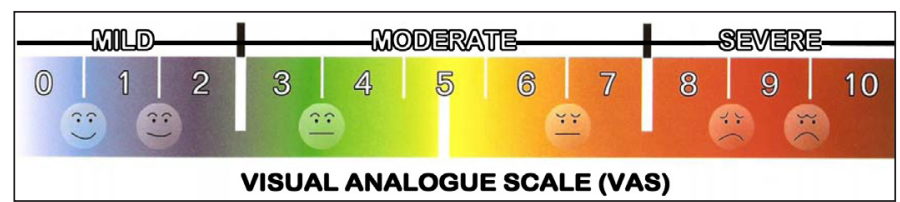

Figure 1 - Visual analogue pain scale.

The indications for surgical treatment were the following: spinal cord compression with myelopathy; spinal instability manifested as fractures, progressive deformation, progressive neurological deficit and intractable pain; radiculopathy with progressive or uncontrollable symptoms; and tumor growth even after radiotherapy or chemotherapy. 
The treatment methods used were: stabilization of the spine with fixation between segments (using pedicle screws or sublaminar wires and Hartshill rectangle); spinal cord decompression together with stabilization; and curative surgery with resection of the tumor lesion.

A retrospective cohort study was conducted, in which the Tokuhashi scores (Box 2, 3 and 4; and Figure 2) were applied retrospectively to all the patients, in order to evaluate the applicability of the scale to the cases studied. The patients' real length of survival was compared with the length of survival that was expected according to the modified Tokuhashi score.

Box 2 - Tokuhashi classification.

\begin{tabular}{|c|c|}
\hline Characteristics & Points \\
\hline \multicolumn{2}{|l|}{1 - General conditions } \\
\hline Poor & 0 \\
\hline Medium & 1 \\
\hline Good & 2 \\
\hline \multicolumn{2}{|l|}{2 - Metastases outside of vertebra } \\
\hline Three or more & 0 \\
\hline One or two & 1 \\
\hline None & 2 \\
\hline \multicolumn{2}{|l|}{3 - Metastases in vertebra } \\
\hline Three or more & 0 \\
\hline One or two & 1 \\
\hline None & 2 \\
\hline \multicolumn{2}{|l|}{4 - Metastases in viscera } \\
\hline Not removable & 0 \\
\hline Removable & 1 \\
\hline None & 2 \\
\hline \multicolumn{2}{|l|}{5 - Site } \\
\hline $\begin{array}{l}\text { Lings, osteosarcoma, stomach, bladder, esophagus } \\
\text { and pancreas }\end{array}$ & 0 \\
\hline Liver, gallbladder and unknown & 1 \\
\hline Others & 2 \\
\hline Kidney and uterus & 3 \\
\hline Rectum, thyroid and breasts & 4 \\
\hline Prostate and carcinoid & 5 \\
\hline \multicolumn{2}{|l|}{6 - Neurological state } \\
\hline Frankel $A$ and $B$ & 0 \\
\hline Frankel B and C & 1 \\
\hline Frankel D and E & 2 \\
\hline
\end{tabular}

Box 3 - Grading of patients' general state according to the Karnofsky scale.

\begin{tabular}{|c|c|}
\hline General condition & Karnofsky \\
\hline Poor & $10-40 \%$ \\
\hline Moderate & $50-70 \%$ \\
\hline Good & $80-100 \%$ \\
\hline
\end{tabular}

Box 4 - Survival according to the modified Tokuhashi index.

\begin{tabular}{|c|c|}
\hline Score & Survival in months \\
\hline $0-8$ points & 6 months \\
\hline $9-11$ points & $6-12$ months \\
\hline $12-15$ points & More than 12 months \\
\hline
\end{tabular}

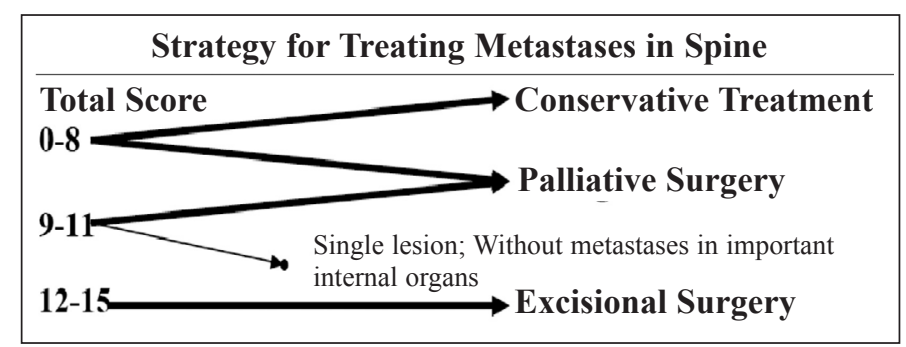

Figure 2 - Strategy for treating metastases according to modified Tokuhashi.

\section{RESULTS}

Out of the total of 157 patients, $82(52.2 \%)$ were female and $75(47.8 \%)$ were male. The mean age was 53.9 years, with a minimum of 15 and maximum of 84 .

Regarding the primary site of the neoplasm, the most frequent sites were the breasts $(25.5 \%)$ and prostate $(21 \%)$. The other cases are specified in Box 5.

Regarding the location of the lesion in the spine, the thoracic region was affected in $66.2 \%$, lumbar region in $65.6 \%$, cervical region in $15.9 \%$ and sacral region in $12.7 \%$ (Box 6). In $50.3 \%$ of the cases, the tumor only involved one segment of the spine; in $39.5 \%$, two segments; $9.5 \%$, three segments; and $0.7 \%$, four segments (Box 7).

All the patients underwent surgical treatment, and the most common form of treatment was spinal cord decompression and fixation with pedicle screws.

The most frequent indication for surgical treatment was intractable pain, which accounted for $89.2 \%$ of the cases. In $39.5 \%$, the indication was paraplegia and in $35.7 \%$, paresthesia. The other symptoms are shown in Table 8. Box 9 shows the number of symptoms presented per patient before the operation. It can be seen that $68.1 \%$ presented two or more symptoms together.

The preoperative Frankel classification is shown in Box 10. 
Box 5 - Primary site for metastases.

\begin{tabular}{|c|c|c|}
\hline $\begin{array}{c}\text { Organ from which metastasis } \\
\text { originated }\end{array}$ & Absolute number & $\%$ \\
\hline Prostate & 33 & 21.0 \\
\hline Breast & 40 & 25.5 \\
\hline Ocular orbit & 2 & 1.3 \\
\hline Multiple myeloma & 14 & 8.9 \\
\hline Palate & 1 & 0.6 \\
\hline Uterus & 9 & 5.7 \\
\hline Rectum & 3 & 1.9 \\
\hline Skin - melanoma & 4 & 2.5 \\
\hline Kidneys & 6 & 3.8 \\
\hline Stomach & 3 & 1.9 \\
\hline Placenta & 1 & 0.6 \\
\hline Lymphoma & 4 & 2.5 \\
\hline Primary site unknown & 20 & 12.7 \\
\hline Bladder & 2 & 1.3 \\
\hline Lungs & 3 & 1.9 \\
\hline Ewing's sarcoma & 2 & 1.3 \\
\hline Retroperitoneal sarcoma & 3 & 1.9 \\
\hline Duodenal papilla & 1 & 0.6 \\
\hline Soft-tissue sarcoma & 1 & 0.6 \\
\hline Testicles & 1 & 0.6 \\
\hline Ovaries & 1 & 0.6 \\
\hline Colon & 2 & 1.3 \\
\hline Parathyroid & 1 & 0.6 \\
\hline Total & 157 & 100.0 \\
\hline
\end{tabular}

Box 6 - Segment of the spine involved; more than one segment could be involved in the same patient.

\begin{tabular}{|c|c|c|}
\hline $\begin{array}{c}\text { Segment of the spine } \\
\text { involved }\end{array}$ & Absolute number & $\%$ \\
\hline 1- Cervical & 25 & 15.9 \\
\hline 2- Thoracic & 104 & 66.2 \\
\hline 3- Lumbar & 103 & 65.6 \\
\hline 4- Sacral & 20 & 12.7 \\
\hline
\end{tabular}

Box 7 - Number of segments of the spine affected per patient.

\begin{tabular}{|c|c|c|}
\hline $\begin{array}{c}\text { Number of segments of the spine } \\
\text { affected }\end{array}$ & $\begin{array}{c}\text { Number of } \\
\text { patients }\end{array}$ & $\%$ \\
\hline 1 & 79 & $50.3 \%$ \\
\hline 2 & 62 & $39.5 \%$ \\
\hline 3 & 15 & $9.5 \%$ \\
\hline 4 & 1 & $0.7 \%$ \\
\hline
\end{tabular}

Box 8 - Preoperative symptoms.

\begin{tabular}{|l|c|c|}
\hline \multicolumn{1}{|c|}{ Symptoms } & Absolute number & $\%$ \\
\hline 1 Pain & 140 & 89.2 \\
\hline 2 Paresthesia & 56 & 35.7 \\
\hline 3 Paresis & 37 & 23.6 \\
\hline 4 Paraplegia & 62 & 39.5 \\
\hline 5 Intestinal constipation & 3 & 1.9 \\
\hline 6 Urine retention & 2 & 1.3 \\
\hline \multicolumn{1}{|c|}{ Total } & 157 & 100 \\
\hline
\end{tabular}

Box 9 - Number of symptoms per patient.

\begin{tabular}{|c|c|c|}
\hline $\begin{array}{c}\text { Number of symptoms } \\
\text { per patient }\end{array}$ & Number of patients & $\%$ \\
\hline 1 & 50 & $31.9 \%$ \\
\hline 2 & 72 & $45.9 \%$ \\
\hline 3 & 34 & $21.6 \%$ \\
\hline 4 & 1 & $0.6 \%$ \\
\hline
\end{tabular}

Box 10 - Preoperative Frankel scale.

\begin{tabular}{|c|c|c|}
\hline Frankel scale & Absolute number & $\%$ \\
\hline A & 10 & 6.4 \\
\hline B & 36 & 22.9 \\
\hline C & 41 & 26.1 \\
\hline D & 25 & 15.9 \\
\hline E & 45 & 28.7 \\
\hline Total & 157 & 100.0 \\
\hline
\end{tabular}

In relation to the improvement of the symptoms after the operation, it was observed that there was partial or full alleviation of the pain in the majority of the cases (52.2\%) (Box 11). The criterion for assessing the postoperative symptoms was the visual analogue pain scale alone (pain was the main symptoms mentioned). No postoperative functional assessment on the Frankel scale was available to us in the patients' medical files; instead, only the pain assessment was available. Because of the retrospective nature of this study, it was thus not possible to make a more detailed analysis on the clinical improvement.

Out of the 157 cases studied, 86.6\% progressed to death. The maximum length of survival was 13.6 years; the minimum was three days and the mean was 13.2 months. Currently, $5.1 \%$ of the patients are still alive, for a maximum time of six years, minimum of 18 months and mean of 3.6 years. The other 13 of the 157 patients were lost from follow-up after a maximum of 6.08 years, minimum of 15 days and mean of 7.4 months (Box 12 and 13). 
The scores among the cases operated according to the Tokuhashi scale presented the following frequencies: up to 8 points, 111 cases; from 9 to 11 points, 43 cases; and from 12 to 15 points, three cases (Box 14).

The mean length of survival in months for all the 157 patients is specified for each of the Tokuhashi groups in Box 15.

Box 11 - Postoperative improvement of pain.

\begin{tabular}{|c|c|c|}
\hline Improvement of symptoms & Absolute number & $\%$ \\
\hline Partial & 41 & 26.1 \\
\hline Full & 41 & 26.1 \\
\hline Absent & 69 & 43.9 \\
\hline Not specified & 6 & 3.8 \\
\hline Total & 157 & 100.0 \\
\hline
\end{tabular}

Box 12 - Clinical evolution of the cases.

\begin{tabular}{|c|c|c|}
\hline Clinical evolution & Number & $\%$ \\
\hline Death & 136 & 86.6 \\
\hline Currently still alive & 8 & 5.1 \\
\hline $\begin{array}{c}\text { Patients lost from } \\
\text { follow-up }\end{array}$ & 13 & 8.3 \\
\hline Total & 157 & $100 \%$ \\
\hline
\end{tabular}

Box 13 - Length of survival in months.

\begin{tabular}{|c|c|c|c|}
\hline & Mean & Maximum & Minimum \\
\hline Patients who progressed to death & 13.2 & 163.0 & 0.1 \\
\hline Patients currently still alive & 44.0 & 73.0 & 18.0 \\
\hline $\begin{array}{c}\text { Patients lost from follow-up } \\
\text { (times refer to period until lost) }\end{array}$ & 7.4 & 17.0 & 0.5 \\
\hline
\end{tabular}

Box 14 - Scores according to the modified Tokuhashi scale in all the groups.

\begin{tabular}{|c|c|}
\hline Tokuhashi score & Number \\
\hline 0-8 points & 111 \\
\hline 9-11 points & 43 \\
\hline $12-15$ points & 3 \\
\hline Total & 157 \\
\hline
\end{tabular}

Box 15 - Length of survival in months according to Tokuhashi scores, obtained by testing the means to investigate differences between the means for each score group, at the significance level of $5 \%$. $P=0.599$.

\begin{tabular}{|c|c|}
\hline Tokuhashi score & Mean length of survival in months \\
\hline 0-8 points & 15.4 \\
\hline 9-11 points & 11.4 \\
\hline $12-15$ points & 12 \\
\hline
\end{tabular}

Figure 3 compares the mean survival in months found in this study with the mean survival expected according to the Tokuhashi scale.

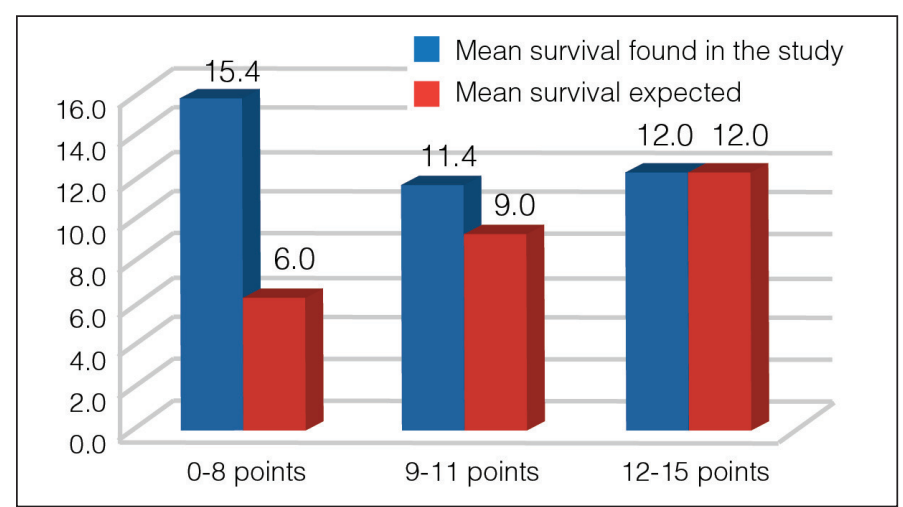

Figure 3 - Comparison between the mean survival in months found in the study and the mean survival expected according to the modified Tokuhashi score.

\section{DISCUSSION}

Primary tumors in the spine are rare and represent less than $10 \%$ of bone tumors. The great majority of vertebral tumor lesions consist of secondary lesions, especially in adult patients ${ }^{(2)}$. Around $50 \%$ to $70 \%$ of the patients who die because of malignant neoplasia present bone metastases in the spine ${ }^{(2,10)}$.

Over recent years, there have been major advances in the staging and treatment of tumor lesions. This has made longer survival possible for individuals with tumors in the spine, and especially for those who present metastatic lesions, who have noticeably increased in numbers over the last few years ${ }^{(4,11)}$.

The literature shows that applying the Tokuhashi score is valid for determining the prognosis for the lives of patients affected by spinal metastases. This subsequently is of assistance in determining whether surgical or conservative treatment is indicated. However, other factors that are not evaluated or included in this and other similar scales, such as the degree of maturity of the neoplasia, stage of the disease at the time of diagnosis and degree of compromising of renal function are also determinants of the prognosis ${ }^{(1)}$.

Evaluations on surgical treatments for spinal tumors present major limitations because of the heterogeneity of the patient samples studied, with regard to the etiology of the tumor lesion. This creates difficulty regarding the final assessment of the results, since it cannot be forgotten that tumors of differing 
etiologies present different biological behavior. It is very difficult to accumulate a significant number of patients with vertebral tumors of the same etiology, and hence the studies that have been carried out present major limitations. With regard to the primary tumor, the data gathered from the patients in the present study were concordant with the literature, given that breast and prostate neoplasia were the most frequent origins for metastases.

Overall, other studies found that $70 \%$ of the cases had metastases located in the thoracic spine, $20 \%$ in the lumbar-sacral region, $10 \%$ in the cervical segment and $17-30 \%$ in more than one segment ${ }^{(2,3)}$. In our sample, the thoracic region was affected in $66.2 \%$, the lumbar-sacral region in $78.3 \%$ and the cervical region in $15.9 \%$, and in $49.7 \%$ of the cases, more than one segment of the spine was compromised. Contrary to the literature, we observed that the metastases were predominantly in the lumbar-sacral region, with a greater number of multiple metastases.

With regard to the treatment, given that the main determining factor for the type of treatment for vertebral metastases is the prognosis, scores such as Tokuhashi help to determine the prognosis for the disease and to choose the therapy. However, they are not the only tool for indicating the type of treatment. Other, separate variables need to be taken into consideration, such as: intractable pain; expansive lesions that do not respond to oncological treatments like radiotherapy, chemotherapy or hormone therapy; and spinal instability and spinal cord compression manifested clinically ${ }^{(1)}$.

Of these symptoms, pain is the main manifestation in patients with metastatic bone lesions. Paraplegia may be another early sign caused by vertebral metastasis. Patients with significant neurological deficits but without paraplegia may present considerable improvement of their deficiencies through surgical treatment that aims to achieve decompression and stabilization. However, there is insufficient evidence to recommend routine surgical intervention for paraplegic patients $^{(2,12,13)}$. In our study, the main symptom reported was also pain, which was present in $89.2 \%$ of the cases. Paraplegia was present in $39.5 \%$, and paresthesia in $35.7 \% ; 68.1 \%$ of the patients presented two or more symptoms in association. Regarding the improvement in symptoms after the operation among our sample, we observed that there was partial or full alleviation of the pain in the majority of the cases $(52.2 \%)$.

Surgical intervention is beneficial in the presence of metastatic disease in the spine, particularly with regard to alleviation of the pain symptoms caused by the metastasis, and to improvement of quality of life. However, there is insufficient evidence to ascertain whether survival is longer after surgery. Thus, surgery in such situations is palliative but improves patients' quality of life, provided that the criteria for its indication are respected ${ }^{(4)}$.

Regarding the indications for treatment in the present study, they were not based primarily on the prognosis for patients' lives, given that in the cases presented here, the scores were applied retrospectively. The parameters for indicating treatment were: neurological deficit, instability due to fractures, or intractable pain that did not respond to conservative analgesia or radiotherapy measures. This approach was shown to be valid after retrospective analysis, given that the patients with poor prognoses achieved better quality of life. The distribution of the Tokuhashi scores for the cases operated at Hospital Erasto Gaertner, in Curitiba, was as follows: 111 cases with up to eight points; 43 cases with 9 to 11 points and three cases with 12 to 15 points, such that scores of 0-8 points had the worst prognosis and 12-15 had the best prognosis. The finding that most of our cases had scores between 1 and 8 represents the reality of an oncological reference hospital, to which cases of greater complexity are referred for evaluation by specialists in this field. However, even though the greatest number of cases belonged to the group with the worst prognosis according to the Tokuhashi scale, we observed that the mean survival in this group (15.4 months) was greater than the expected mean survival for the same category (less than six months). In the other groups, the expected survival according to the Tokuhashi score was longer: 6-12 months for the group with 9-11 points and more than 12 months for the group with 12-15 points, and we observed that for our sample, the mean survival for these groups was within the expectations: 11.4 and 12 months respectively.

We believe that although surgical treatment for spinal tumors is of large magnitude and not free from complications, it should not be postponed in the 
presence of the indications mentioned earlier, since accomplishing it may satisfactorily change the clinical evolution of this group of patients. However, surgical indications based on determining the patient's prognosis and expected length of survival using scores like Tokuhashi were not shown to be applicable in this study, considering that patients who, according to the modified Tokuhashi score, would not be indicated for surgery because of the poor prognosis (score from 0 to 8 ) underwent operations within our service and achieved longer survival than would have been expected using the score. Thus, our study showed that there was also a benefit from surgically treating the patients whose prognoses were worse.

In this manner, in metastatic disease, each patient should be considered individually, and the decision regarding the best treatment method should be made after complete staging. Although this treatment is palliative, it is important to avoid an attitude of "disbelief and disregard". The consequences of such an attitude could be disastrous and irreversible, and might lead patients and their families into inhuman situations.
Despite the existence of many scales for assisting in making therapeutic indications and their validity for determining prognoses, good sense should be used in making decisions regarding the treatment objectives, methods and approaches, and this always requires a multidisciplinary team. Maintaining an active and proactive attitude regarding treatments for these metastases may help to improve the patients' quality of life, sometimes for a period of years.

\section{CONCLUSION}

Although this study was a retrospective analysis and the therapeutic indications were not applied based on the modified Tokuhashi scores, we formed an impression that the survival was longer in the group with worst prognosis than would be expected from the scores. Thus, differing from the non-surgical approach recommended for patients with lower scores, this group in our study was sent for surgery with better results than those found for non-operated patients reported by Tokuhashi .

\section{REFERENCES}

1. Sansão CC, Lehoczki MA, Boechat RCB, Landim E, Cavali PTM, Veiga IG, et al. Estudo da aplicabilidade do escore de Tokuhashi modificado nos pacientes tratados cirurgicamente de metástases vertebrais. Rev Coluna 2008;7(2)167-70.

2. Joaquim AF, Paula FA, Anderle DV, Zambell HJL, Maldaun MVC. Metástases na coluna vertebral. Rev Neurocienc. 2007;15(3):240-5.

3. Kilmo P, Kestle JR, Schmidt MH. Treatment of metastatic spinal epidural disease: a review of the literature. J Neurosurg Focus. 2003;15(5):E1,1-9.

4. Ryken TC, Eichholz KM, Gerszten PC, Welch WC, Gokaslan ZL, Resnick DK. Evidence-based review of the surgical management of vertebral column metastatic disease. J Neurosurg Focus. 2003;15(5):E11.

5. North RB, LaRoca VT, Schwartz J, North CA, Zahurak M, Davis RF, McAfee PC. Surgical management of spinal metastases: analysis of prognostic factors during a 10-year experience. J Neurosurg Spine. 2005;2(5):564-73.

6. Tomita K, Kawahara N, Kobayashi T, Yoshida A, Murakami H, Akamaru T. Surgical strategy for spinal metastases. Spine (Phila PA 1976). 2001;26(3):298-306.
7. Tokuhashi Y, Matsuzaki H, Oda H, Oshima M, Ryu J. A revised scoring system for preoperative evaluation of metastatic spine tumor prognosis. Spine (Phila PA 1976). 2005; 30(19):2186-91.

8. Ulmar B, Huch K, Naumann U,Catalkaya S, Cakir B, Gerstner S, et al. Evaluation of the Tokuhashi prognosis score and its modifications in 217 patients with vertebral metastases. Eur J Surg Oncol. 2007;33(7):914-9.

9. Malawski SK. The results of surgical treatment of primary spinal tumors. Clin Orthop North Am J. 1991;272:5057.

10. Ecker RD, Endo T, Wetjen NM, Krauss WE. Diagnosis and treatment of vertebral column metastases. Mayo Clin Proc. 2005;80(9):1177-86.

11. Ratliff JK, Cooper PR. Metastatic spine tumors. South Med J. 2004;97(3):246-53.

12. Kienstra GE, Terwee CB, Dekker FW, Canta LR, Borstlap AC, Tijssen CC, et al. Prediction of spinal epidural metastases. Arch Neurol. 2000;57(5):690-5.

13. Abraham JL. Assessment and treatment of patientes with malignant spinal cord compression. J Support Oncol. 2004;2(5):377-88. 